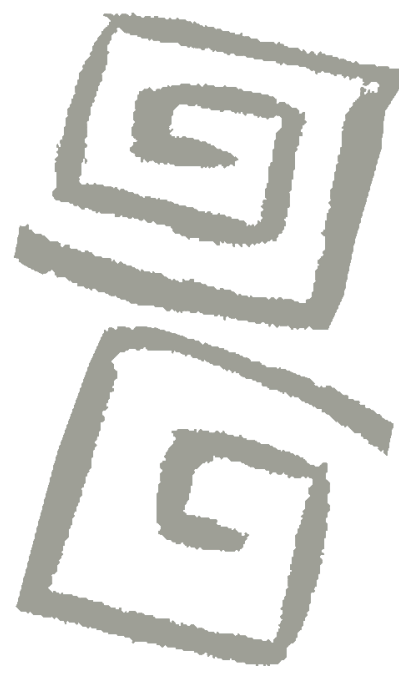

\title{
Entre la finca, la fábrica y la casa: el trabajo productivo y reproductivo de trabajadoras agrícolas migrantes en Mendoza (Argentina) y su incidencia en la salud-enfermedad
}

\author{
Among the farm, the factory, and home: productive \\ and reproductive work of female migrant farmworkers \\ in Mendoza (Argentina) and its impact in the health- \\ disease process
}

\author{
María Florencia Linardelli ${ }^{1}$
}

'Licenciada en Trabajo Social. Especialista en Salud Mental. Becaria Doctoral Consejo Nacional de Investigaciones Científicas y Técnicas, con sede en Instituto de Ciencias Humanas, Sociales y Ambientales, Mendoza, Argentina. $\triangle$ (iD)
RESUMEN A partir de las últimas décadas del siglo XX asistimos a profundas transformaciones del trabajo agrícola en América Latina, que han incidido decisivamente en la salud de las y los trabajadores. Estos procesos han tenido implicancias específicas para las trabajadoras agrícolas, quienes afrontan la condición de precariedad laboral del sector, a la vez que experimentan desigualdades que las afectan distintivamente. Este artículo propone analizar conjuntamente los procesos de trabajo productivo y reproductivo de trabajadoras agrícolas migrantes residentes en Mendoza (Argentina), buscando dilucidar la incidencia de esta doble carga en su salud-enfermedad. A partir del trabajo de campo, realizado desde el año 2014 en la localidad agrícola de Ugarteche, Luján de Cuyo, mediante un enfoque cualitativo apoyado primordialmente en la estrategia biográfica, y con la colaboración de herramientas conceptuales feministas, analizamos las relaciones entre trabajo y salud desde la forma en que estos procesos son narrados por las mujeres migrantes. Los resultados muestran, por una parte, que los procesos de trabajo que impactan en su salud incluyen el empleo y las labores reproductivas, y por otra, describen los daños, enfermedades y padecimientos vinculados al trabajo conjunto en fincas, fábricas y hogares.

PALABRAS CLAVES Mujeres Trabajadoras; Enfermedades de los Trabajadores Agrícolas; Salud de los Trabajadores; Condiciones de Trabajo; Argentina.

\begin{abstract}
Starting in the last decades of the 20th century, deep transformations have occurred in Latin American agricultural work, with decisive impacts on workers' health. These processes have had specific implications for female agricultural workers, who face the precarious working conditions common to all agricultural workers as well as inequalities that affect them distinctly. This article seeks to analyze the productive and reproductive work of migrant female farmworkers residing in Mendoza (Argentina), in order to elucidate the impact of this double workload on their health-disease processes. Fieldwork was carried out in 2014 in the agricultural town of Ugarteche, Luján de Cuyo, using a qualitative method supported primarily in a biographical approach. With the collaboration of feminist theoretical tools, we analyzed the relation between work and health based on the way these processes are narrated by migrant women. The results show that the work processes impacting their health include both employment and reproductive labor, and describe the harm, diseases, and illnesses linked to combined work in farms, factories and homes.
\end{abstract}

KEY WORDS Women, Working; Agricultural Workers' Diseases; Occupational Health; Working Conditions; Argentina. 


\section{INTRODUCCIÓN}

Desde los últimos decenios del siglo XX asistimos a profundas transformaciones en el mundo del trabajo, que han impactado decisivamente en la salud-enfermedad de las y los trabajadores. En América Latina, la globalización neoliberal ha generado procesos de reconcentración de la tierra, deterioro de las condiciones laborales de las personas asalariadas agrícolas, aumento de las desigualdades en el acceso a bienes fundamentales para la supervivencia, y la migración de familias campesinas que se vinculan al trabajo asalariado agrícola en condiciones de creciente precariedad. Estos procesos no han sido sexualmente neutros. Las mujeres que se desempeñan como asalariadas del agro comparten la condición de precariedad laboral del sector, pero experimentan desigualdades sexo-genéricas que las afectan distintivamente: falta de cobertura en eventos reproductivos, violencia en el trabajo, asignación a los puestos peor remunerados y la invisibilización de sus calificaciones laborales por ser consideradas habilidades femeninas "naturales".

La participación creciente de mujeres en flujos migratorios y en el empleo agrícola no ha implicado una ruptura con la tradicional división sexual y social del trabajo, sino que ha recreado su asignación al trabajo desvalorizado $^{(1)}$ y a las labores domésticas. Las migrantes que se desempeñan como asalariadas rurales en Mendoza, a la par de largas jornadas de trabajo en el campo, en sus hogares son las responsables principales de las tareas de reproducción cotidiana y del cuidado de sus grupos de pertenencia. Esto acontece en contextos de privación económica y de un limitado acceso a servicios sanitarios y políticas de protección social, debido a su condición de migrantes ${ }^{(2)}$. Las características de trabajo mencionadas inciden directamente en su salud-enfermedad: sus trayectorias de vida se encuentran cruzadas por distintos padecimientos, enfermedades y dolencias, que encuentran poca recepción en las instituciones sanitarias a las que pueden acudir.
Distintas investigaciones abocadas a la salud de las trabajadoras agrícolas exploran los riesgos laborales a los que se ven expuestas, como los efectos de la manipulación de agrotóxicos y pesticidas ${ }^{(3,4)}$, las largas jornadas de trabajo, la presión del pago a destajo y la falta de cobertura de seguridad social| ${ }^{(5,6)}$. Otros estudios, analizan las dificultades en el acceso a los servicios de salud y la situación de su salud reproductiva $a^{(7,8,9,10,11)}$. Gran parte de estas investigaciones se abocan al trabajo remunerado y tienden a desconocer las cargas domésticas que sostienen las mujeres. Debido a esta brecha que abren los estudios disponibles, en este artículo proponemos analizar conjuntamente los procesos de trabajo productivo y reproductivo de trabajadoras agrícolas migrantes residentes en Mendoza, buscando dilucidar la incidencia de esta doble carga en su salud-enfermedad. A partir de sus narrativas biográficas, analizamos las relaciones entre trabajo y salud, considerando conjuntamente las condiciones de su labor en fincas, fábricas y hogares.

\section{METODOLOGÍA}

El artículo presenta los hallazgos de una investigación, más amplia y en curso, sobre las experiencias de salud-enfermedad-cuidado de mujeres migrantes vinculadas al empleo agrícola en Mendoza. Tal estudio, denominado "Salud, ruralidad y género: el encuentro entre los saberes populares y los saberes médico hegemónicos en espacios rurales de Mendoza, desde una perspectiva de género" se realiza gracias a una beca doctoral otorgada por el Consejo Nacional de Investigaciones Científica y Técnicas de Argentina.

Desde el punto de vista metodológico, el diseño que organiza el estudio es cualitativo y se apoya especialmente en el enfoque biográfico, como un modo de acceder a experiencias de sujetos y grupos sociales subordinados que han sido históricamente privados de la palabra pública(12,13). Mediante los relatos de vida es posible captar aspectos de la existencia de difícil acceso desde otras 
herramientas, como la vida cotidiana y las emociones, por lo que son particularmente aptos para la investigación con perspectiva de género ${ }^{(12)}$. El trabajo de campo de la investigación se desarrolla desde el año 2014 en la localidad de Ugarteche, departamento de Luján de Cuyo. Esta zona, situada en el oasis norte de la provincia de Mendoza, Argentina, a cuarenta kilómetros de la ciudad capital, constituye un enclave de migración limítrofe e interna, y mantiene una importante tradición agrícola en torno a los cultivos de vid y hortalizas ${ }^{(14)}$. Se trata de una comunidad que se gestó de la mano de la migración sostenida de trabajadoras/es de nacionalidad boliviana y actualmente resulta un territorio socialmente complejo, con escasa presencia de instituciones y servicios públicos, crecientes problemas de pobreza y precarias condiciones de vivienda e infraestructura. Es un paisaje heterogéneo, rodeado por viñedos destinados a la producción de vinos de exportación, cultivos de hortalizas para el mercado interno e internacional y un rastro menor de pequeña producción hortícola que ofrece sus productos en la feria local.

El material de campo está constituido por dos fuentes. Por un lado, narrativas obtenidas en el contexto de sucesivas entrevistas en profundidad a cinco trabajadoras que residen en dicha localidad. Siguiendo el criterio de maximizar las diferencias, hemos buscado entrevistadas que den cuenta de un rango amplio de experiencias individuales ${ }^{(11)}$ : sus edades se encuentran entre los 29 y los 52 años; tienen diversas inserciones laborales agrícolas (en fincas y fábricas de empaque); una de ellas es migrante interna (de la provincia de Salta) y las demás son originarias de distintas localidades rurales de Bolivia. Por otro lado, durante dos años hemos realizado observaciones en el contexto de un grupo de mujeres migrantes, que se reúnen durante el período bajo de la temporada de trabajo agrícola para recuperar técnicas tradicionales de tejido andino y producir ropa de abrigo para sus familias o para la venta. Este espacio nos ha permitido un acercamiento a su cotidianidad, a las relaciones que entablan entre sí y con otros actores de la comunidad y a las diversas estrategias que despliegan para sostener sus hogares en períodos de desempleo.

Parte de los datos mencionados en este artículo también han sido abordados en un trabajo anterior orientado a analizar el rol de las migrantes bolivianas a cargo del cuidado de familiares con alguna enfermedad ${ }^{(2)}$. Todas las actividades descriptas han contado con el consentimiento de las participantes. El proyecto de investigación en su conjunto ha sido evaluado por la comisión de otorgamiento de becas del Consejo Nacional de Investigaciones Científicas y Técnicas, que incluye la revisión de aspectos éticos de la investigación. A lo largo del texto, presentamos fragmentos textuales del discurso de cada entrevistada, quienes son presentadas mediante seudónimos, a fin de preservar su identidad.

En términos teóricos la relación entre trabajo y salud resulta un tópico de gran centralidad en los estudios sociales abocados al campo de la salud. En efecto, el trabajo ha sido considerado desde mediados de 1970 por autoras y autores latinoamericanos del campo de la medicina social y la salud colectiva como uno de los principales determinantes del proceso de salud-enfermedad de las colectividades humanas ${ }^{(15,16)}$. Desde estas perspectivas, la salud-enfermedad no se reduce a la enfermedad clínica, sino que implica diversos niveles de malestar corporal y psíquico. Más que un estado, constituye un devenir en el marco de procesos históricos, y debe ser abordada tomando como punto de partida grupos definidos en función de su inserción específica en procesos sociales críticos $^{(17,18)}$. Paralelamente, desde el campo de los estudios de la mujer comenzaron a realizarse trabajos académicos orientados al análisis crítico de los procesos de saludenfermedad, a las relaciones entre mujeres y sistema sanitario y a la incidencia de las desigualdades sexo-genéricas en la salud. Por la misma época, pensadoras feministas pusieron en el centro del debate las relaciones entre el trabajo productivo y reproductivo, la división sexual del trabajo y sus consecuencias en la vida de las mujeres ${ }^{(19)}$. Recogiendo estas tradiciones, hacia finales del siglo XX las investigaciones sobre la salud 
de las mujeres trabajadoras cobran peso propio y surgen múltiples abordajes teóricos y empíricos ${ }^{(20,21,22,23,24,25,26,27,28)}$. En este artículo, recuperamos algunos aportes conceptuales que permiten comprender las relaciones entre trabajo y salud como vínculos marcados con el peso de la diferenciación sexual.

Para la teoría feminista, la diferenciación basada en el sexo no es un dato biológico o dado, sino "una de las formas más extendidas de explotación humana arraigada en la interacción personal entre los sexos, en instituciones sociales básicas, como la familia, y enraizada en estructuras económicas y políticas" $^{\prime \prime 29)}$. La subordinación de las mujeres adopta formas diversas de acuerdo a su ligazón con otros sistemas de dominación social, como la clase y la racialización ${ }^{(30,31)}$ y se apoya en gran medida en una base económica definida por la organización de la producción y de la reproducción ${ }^{(29)}$. Un punto central de este debate ha sido la división sexual del trabajo, es decir, la adscripción prioritaria de varones a la producción y de mujeres a la reproducción, con base en relaciones sociales de sexo profundamente desiguales $^{(19,32)}$. Frente al supuesto de que esta división del trabajo según el sexo es algo natural, asentado en la fisiología de la mujer y a su papel en la reproducción (biológica), las feministas han señalado que las mujeres no eligen su posición subordinada en la división social del trabajo de manera "natural" o altruista, por sus preferencias, ni por su presunta menor productividad, sino que esta ha sido históricamente construida para mantener el poder social masculino ${ }^{(33)}$.

A esta discusión se encuentran articulados los debates sobre el concepto de trabajo. Desde la década de 1970, los estudios feministas señalaron que las teorías económicas clásicas, al restringir el concepto de trabajo a la fabricación de mercancías, ignoraron la producción realizada en el hogar y el modo en que se articula a la reproducción del sistema capitalista ${ }^{(34,35,36)}$. Este sesgo impide visualizar la decisiva aportación económica de las mujeres a la reproducción social y, de esta manera, refuerza su subordinación ${ }^{(35)}$. "Designar por trabajo a la actividad desarrollada en el mercado y conceptualizar como notrabajo a aquella realizada en los hogares, ha contribuido a consolidar una valoración distinta tanto para la actividad, como para las personas que la realizan"(37). Esta escasa valoración, además se vincula con su no remuneración y con la sobrecarga del trabajo (gratuito) que las mujeres realizan. Pero además se trata de una subvaloración paradójica si consideramos la importancia social de estas actividades, ya que los hogares no se sustentan solo por el ingreso percibido en los salarios, sino que este se combina con trabajo reproductivo destinado a producir los bienes y servicios necesarios para la subsistencia y bienestar de los miembros del hogar, labor que es desempeñada mayoritaria o exclusivamente por mujeres ${ }^{(37,38)}$

A la par del reconocimiento del trabajo de las mujeres en los hogares, los estudios de género y feministas han hecho visible su implicación activa en el mundo de la producción. Las investigaciones sobre esta participación conducen a que se comience a hablar de feminización de ciertos fenómenos sociales: de las migraciones, de la supervivencia y del trabajo asalariado rural. Estudios migratorios sostienen que desde finales del siglo $X X$ asistimos a un proceso de "feminización de las migraciones" que implica no solo el crecimiento de la cantidad de mujeres que intervienen en los movimientos poblacionales de manera autónoma, sino también un proceso de visibilización de su participación histórica, que había permanecido en el anonimato de las teorías clásicas, oculta tras el rótulo de acompañantes familiares ${ }^{(39,40,41)}$.

Para Saskia Sassen ${ }^{(42)}$, las transformaciones en la presencia de mujeres en los flujos migratorios pueden ser interpretadas en el marco de lo que llama "feminización de la supervivencia". La autora afirma que la creciente integración de mujeres en los circuitos transfronterizos se vincula con los efectos del ajuste estructural en los países del sur y con el aumento del desempleo, hechos que han multiplicado la presión que recae sobre ellas para encontrar modos de asegurar la supervivencia doméstica. Ese contexto explica el surgimiento de una amplia variedad de 
circuitos globales alternativos de generación de ingresos, que operan en la denominada economía sumergida y se integran por actividades lícitas e ilícitas: desde "exportaciones" organizadas de cuidadoras, enfermeras o empleadas domésticas, hasta la trata con fines de explotación sexual o laboral. La feminización de la supervivencia refiere, entonces, al hecho de que la economía doméstica y la comunitaria dependen de manera creciente de las mujeres. Lo mismo sucede con los gobiernos, que requieren de las remesas que ellas generan en los circuitos transfronterizos ${ }^{(42)}$.

Por su parte, Sara Lara ${ }^{(43)}$ se refiere a la feminización del trabajo asalariado rural. La autora puntualiza que, en América Latina, la reconversión productiva de la agricultura se acompañó de la feminización del trabajo, especialmente, en los cultivos no tradicionales. El sector agroexportador tomó un papel preponderante por sus "ventajas comparativas", sustentadas en el clima, los recursos naturales y la existencia de una mano de obra barata y extremadamente flexible que comenzó a suplir la falta de tecnología. El agro de la región basó su inserción en el mercado internacional en una flexibilidad "salvaje" de la mano de obra, que mantiene a grandes masas de personas (especialmente mujeres, migrantes y jóvenes) en trabajos temporales, con largos períodos de desempleo y formas de trabajo sumamente precarias ${ }^{(43)}$.

En relación con lo hasta aquí expuesto, María Mies ${ }^{(44)}$ considera que la combinación del limitado acceso a los beneficios económicos del sistema formal de empleo junto con la responsabilidad por las necesidades básicas de sobrevivencia de sí mismas y sus descendientes permite la superexplotación de las mujeres. El concepto de superexplotación posee una profunda raigambre en el marxismo y ha suscitado múltiples debates. Si bien el objeto de este artículo no consiste en exponerlos, señalaremos brevemente a las y los autores que luego de Karl Marx, abordaron esta noción. Uno de los más relevantes es Claude Meillassoux, quien en su libro $\mathrm{Mu}$ jeres, graneros y capitales ${ }^{(45)}$ analiza las relaciones entre el sector doméstico y capitalista en la economía de los países colonizados y afirma que el primero es explotado por el segundo, provocando una reproducción de la fuerza de trabajo que no entra directamente dentro de sus costos. Dicha explotación no es transitoria, sino inherente a la reproducción capitalista, a la vez que constituye una perpetuación de la acumulación originaria. María Mies ${ }^{(44)}$, por su parte, en Patriarchy and accumulation on a world scale. women in international division of labour afirma que el proceso de producción capitalista comprende la superexplotación de los trabajadores no asalariados (mujeres y campesinos) sobre la cual se sostiene la explotación del trabajo asalariado. Para la autora se trata de una superexplotación porque no se basa en la apropiación (por el capitalista) del trabajo excedente, sino del tiempo y el trabajo necesarios para la propia supervivencia de la gente, que además no se compensa con un salario, sino que está principalmente determinada por la fuerza o por instituciones coercitivas. Mies enfoca su preocupación en las mujeres del sur del mundo, especialmente, las mujeres rurales, y en las características que asumen sus labores en el capitalismo. Finalmente, Ruy Mauro Marini en Dialéctica de la dependencia ${ }^{(46)}$ utiliza la noción para explicar la transferencia de valor desde los países periféricos hacia los centrales, sustentada en la apropiación extraordinaria de plusvalía en los primeros. En términos de Marini, la superexplotación se define por la mayor explotación de la fuerza física del trabajador y tiende a expresarse en el hecho de que la fuerza de trabajo se remunera por debajo de su valor real.

La noción de sobreexplotación también ha sido utilizada por autoras como Silvia Federici( ${ }^{(38)}$ para designar la situación en que se encuentran las mujeres trabajadoras del sur del mundo, quienes deben garantizar la sobrevivencia de sus grupos en condiciones laborales y domésticas cada vez más precarias, que demandan una creciente intensificación de su esfuerzo y la extensión de su jornada de trabajo. Estas categorías indican que la integración de mujeres al empleo asalariado en los países del sur global, como productoras de mercancías baratas para la exportación, no 
solo es el resultado de sus luchas por participar en la producción y obtener su propio sustento. Se trata, además, de un fenómeno vinculado a la reestructuración de la economía mundial ${ }^{(36)}$, basada en la expansión acelerada del mercado de trabajo, el crecimiento del mundo proletario y la recreación de la división sexual del trabajo en el ámbito de la producción.

Los aspectos señalados nos permiten advertir las limitaciones de aquellos enfoques que analizan las relaciones entre el trabajo y la salud de las mujeres desconociendo las cargas domésticas-reproductivas y considerando únicamente el empleo remunerado. Por tanto, a continuación, examinamos las condiciones de trabajo productivo y las particularidades de las labores reproductivas de las trabajadoras agrícolas migrantes en Mendoza, las conexiones y tensiones entre estas esferas, para luego abordar los daños, malestares y padecimientos que se vinculan con su trabajo.

\section{El trabajo asalariado de las mujeres en la agricultura: La inserción de mujeres migrantes en circuitos feminizados y racializados del mercado de trabajo agrícola}

Los procesos de globalización neoliberal y ajuste estructural transformaron decisivamente la agricultura de América Latina. El dominio del capital multinacional sobre el agro se acompañó de la expulsión de medianos y pequeños productores, la difusión creciente del trabajo asalariado y la precarización del empleo rural, junto con las continuas migraciones campo-ciudad o a través de las fronteras $^{(47)}$. En este contexto, comenzó a registrarse un aumento de la emigración rural y del trabajo asalariado de mujeres en el agro ${ }^{(48,49)}$. El nuevo siglo profundizó estas tendencias y para el caso argentino- demarcó un campo profundamente desigual en función de las posibilidades de acceso de los actores agrícolas a la modernización biotecnológica ${ }^{(50,51)}$.

La "modernización" de la producción coexiste con prácticas que ya se consideraban eliminadas: además de la flexibilización y la precariedad, persisten condiciones laborales cercanas al trabajo esclavo ${ }^{(52)}$. Otro rasgo distintivo del mercado de trabajo agrícola regional es el uso de la mano de obra sustentado en una marcada segmentación racial y sexual las y los trabajadores, se trata de "una organización del trabajo que sin utilizar la violencia directa, entendida como agresiones físicas, pone en marcha un sistema de dominación en el cual convergen: clase, género y etnia [...] que legitima no solo el lugar que ocupan en el trabajo sino también en la

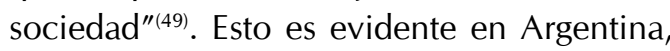
donde las migrantes bolivianas por su sexo, clase y origen étnico, se han incorporado fundamentalmente al mercado informal de trabajo en la agricultura, el comercio y el servicio doméstico ${ }^{(53)}$, como también a los talleres clandestinos de producción textil ligados al tráfico de personas, trata y reducción a la servidumbre ${ }^{(54)}$.

En Mendoza, la presencia creciente de migrantes de Bolivia y del norte argentino se ha tornado típica en distintas etapas de la producción de vid, hortalizas y frutas. Desde la década de 1930, pero particularmente a partir de 1950, en la provincia comienza a crecer aceleradamente la migración de personas de nacionalidad boliviana para la cosecha de vid ${ }^{(55)}$. De manera más reciente, se han creado nichos específicos de empleo para las mujeres como mano de obra transitoria en la agroindustria abocada a productos de exportación ${ }^{(56)}$. Además, esta provincia presenta un particular contexto legal por el cual, debido a presiones corporativas de empresarios vitivinícolas, la vigencia de la ley nacional que protege el trabajo agrícola ha sido suspendida para ese sector productivo, mayoritario y dominante en la provincia. Según la Ley 26727 de Régimen de Trabajo Agrario aqueIlas actividades que tuviesen convenciones colectivas de trabajo anteriores a un decreto regulador de la actividad de 1980, podían continuar bajo esos regímenes. Tal es el caso de la vitivinicultura mendocina, cuyos empresarios aducen la existencia de convenios colectivos de la década de 1970 que los eximirían de ajustarse a la nueva normativa, claramente más favorable a los derechos de las y los trabajadores. 
Las mujeres que han aportado sus relatos de vida presentan trayectorias de vida diversas e integran grupos domésticos con características diferentes. Sandra es la menor de todas, también la que migró más recientemente. Llegó a Mendoza en 2006 desde su Potosí natal; tiene 29 años y es madre de cinco hijos e hijas cuyas edades van desde los 3 meses hasta los 15 años; convive con ellos y ellas junto a su marido. Sonia, de 35 años, migró hacia Argentina desde Potosí a los 16 años, junto a su madre, su padre, hermanas y hermanos. Actualmente está separada y reside con sus cuatro hijas e hijos de entre 5 y 18 años. Es la única de las mujeres entrevistadas que ha vivido y trabajado en zonas urbanas, desempeñándose en el servicio doméstico durante su adolescencia. Rita tiene 37 años y también es potosina; llegó a la Argentina a los 14 años en compañía de su hermana mayor. Juntas se movieron por distintos puntos del país al ritmo de los cultivos de tabaco, zanahoria y vid. A los 18 años formó pareja con quien convive hasta la actualidad junto a sus cinco hijos e hijas (cuyas edades van de los 2 a los 19 años) y dos nietas (una de ellas de tres años y la más pequeña de 6 meses). Es el principal sostén de su hogar, ya que su compañero sufrió un accidente laboral en la construcción y no pudo volver a trabajar. Además, es una figura central en la crianza de sus nietas. Rosa, de 40 años, es la única de las trabajadoras nacida en Argentina, en una localidad fronteriza de la provincia de Salta Ilamada Santa Victoria. Se fue de su pueblo natal a los 22 años junto a su pareja y una bebé de un año, para trabajar como obrera "golondrina en las cuadrillas de zanahoria", según sus propias palabras. Hoy convive con su marido y tres de sus cuatro hijos e hijas y es una abuela presente en el cuidado de sus tres nietas. Alba, de 52 años, es la mayor de las mujeres entrevistadas y la que más tiempo ha vivido en Mendoza. Migró por primera vez a los 8 años con todo su grupo familiar. Luego de tres años regresó a su pueblo en Cochabamba y permaneció allí cuatro años con su madre y hermanos, tras la repentina muerte de su padre. A los 15 años volvió a Mendoza "andábamos en las carpas, trabajábamos, cuidaba a mis hermanos y los mandaba a la escuela" cuenta. Actualmente Alba convive con su marido, un hijo y una nieta. Es la única que se ha retirado de la actividad remunerada y se encuentra abocada a la crianza de la niña. Un rasgo común de las entrevistadas es su pertenencia a pueblos indígenas y que, en sus lugares de origen, integraban unidades domésticas campesinas. Desde niñas trabajaron la tierra y se encargaron del pastoreo de sus animales. Las cuatro mujeres nacidas en Bolivia tienen como primera lengua el quechua, particularmente Sandra y Rita aprendieron a hablar español fluidamente al llegar a Argentina. Cabe señalar que, si bien las parejas de todas las entrevistadas fueron trabajadores agrícolas en el pasado, en la actualidad ninguno permanece en el sector y laboran en la construcción y el transporte por cuenta propia.

Más allá de la diversidad de trayectorias, en la actualidad las mujeres entrevistadas que se encuentran activas se emplean en dos tipos de actividades: en viñedos o "las fincas" -según sus términos- en tareas de pleno campo, y en galpones de selección y empaque de fruta en fresco para la exportación o "la fábrica", de acuerdo a las trabajadoras. Ocasionalmente, combinan estas actividades con tareas en otros cultivos como tomate, cebolla y ajo. El acceso al empleo en la fábrica se asocia al logro de cierta estabilidad de residencia en Mendoza, luego de períodos de mayor movilidad territorial asociada al empleo estacional en la producción de cítricos, tabaco y hortalizas. Desde que residen en forma permanente en la provincia sostienen un ciclo de trabajo que presenta una relativa regularidad anual. Entre los meses de setiembre y diciembre realizan tareas en las viñas, como podar, atar la vid, desbrotar, subir o bajar mallas antigranizo, reparar mangueras de riego por goteo. A partir de enero inician el trabajo de selección y empaque de frutas en la fábrica, actividad que se extiende aproximadamente hasta el mes de marzo. En dicho mes vuelven a las viñas para la cosecha, combinando este empleo con jornadas de trabajo en el galpón de empaque, si hubiere una continuidad en la producción. Este 
ciclo finaliza aproximadamente en mayo, así durante junio, julio y agosto las migrantes se abocan a la búsqueda de ingresos alternativos mediante distintas actividades, fundamentalmente el comercio de productos de elaboración propia (textiles, tejidos y comidas) en la feria local. Este período no resulta una fase inactiva para las mujeres, como señalan algunos estudios sobre jornaleras agrícolas ${ }^{(7)}$, aunque supone una merma en la cantidad de horas destinadas al trabajo remunerado y un aumento de las actividades reproductivas y de cuidado.

En este trabajo nos enfocamos en las fincas y las fábricas, ya que las estrategias de trabajo por cuenta propia que realizan las mujeres durante el período bajo de empleo agrícola presentan una diversidad que requeriría de un análisis particular. Las fincas y las fábricas son espacios en los que se juegan condiciones de trabajo diferentes, además de ser significados de manera diversa por las trabajadoras. Incluso se trata de actividades productivas regidas por distintas normativas laborales. No obstante, presentan algunos puntos comunes. En Mendoza -especialmente en la localidad de nuestro estudio- los dos ámbitos incorporan a mujeres migrantes de manera creciente; incorporación que se rodea de mitos o narrativas de etnicidad ${ }^{(57)}$ y género. Diversos trabajos han abordado los procesos clasificatorios que pesan sobre las y los trabajadores de nacionalidad boliviana, en función de los cuales se les atribuye una capacidad inherente para desempeñarse en las cosechas agrícolas, sustentada en su mayor capacidad de trabajo, resistencia física y sumisión ${ }^{(57,58)}$. Otras autoras han analizado los estereotipos de género sostenidos por el empresariado agroindustrial, que contrata mujeres por considerar que poseen capacidades "innatas" de delicadeza, cuidado y compromiso con el resultado final de su tarea ${ }^{(56,59,60)}$.

En el caso de las migrantes entrevistadas, si bien estos discursos forman parte de sus percepciones en torno de las características que ostentan como trabajadoras, en sus relatos aparecen otros elementos mediante los cuales significan su inserción en fincas y fábricas:

\begin{abstract}
...las bolivianas trabajamos porque queremos, porque necesitamos, por necesidad. Nosotros los bolivianos más que todo somos de poner empeño al trabajar, tú ves acá somos treinta mujeres. Ahora de tu país ¿cuántas personas trabajan acá? Usted va a una finca encargados son paisanos [originarios de Bolivia], vas al viñedo encargados son paisanos, gente que trabaja en la cosecha, son encargados paisanos, en el ajo son paisanos. ¿Por qué les quieren más a los paisanos? Porque somos gente honrada y trabajadora, es la única razón que yo te puedo dar. (Sonia, 35 años)
\end{abstract}

Entre las características que inclinan a los empresarios a la contratación de migrantes de nacionalidad boliviana, Sonia destaca atributos como la honradez y la capacidad de trabajo, pero también atribuye el empeño con que realizan su labor a la necesidad. De esta manera, en su reflexión, pone en juego la consideración de las condiciones de vida y las posibilidades de empleo que tienen las y los migrantes. En lo que hace a la preferencia patronal por emplear a mujeres, las entrevistadas enuncian:

En la viña también, mujeres nada más quieren, no quieren los hombres, porque dicen que son flojos para trabajar, los varones no son responsables... eso dicen los encargados. "Yo prefiero trabajar con mujeres que trabajar con hombres, porque las mujeres son responsables para trabajar", dicen. (Rita, 37 años)

Otra de las entrevistadas puntualiza:

Hace mucho la viña era para hombres nomás, pero ahora hay muchas más mujeres. Los patrones trabajan más tranquilos... no contestamos mucho, los hombres se quejan de la hora, quieren salir... nosotras trabajamos para sacar tarea, para terminar. Las mujeres sacamos más rápido la tarea que los hombres. Las mujeres hasta podan ahora. (Sandra, 29 años) 
En un sentido similar, Rosa confirma lo señalado por las otras entrevistadas y agrega:

Dicen que algunas fincas no quieren a los hombres, porque los hombres no hacen bien los trabajos. $Y$ en la fábrica, ¡uuuh! las mujeres son en cantidad, hay muchas más mujeres que hombres. Hombres hay muy pocos, los hombres no están en la cinta [de producción]. Todas las que están en las cintas son mujeres nomás. Todos los hombres que hay están en las máquinas, están en la limpieza. O los encargados por ahí...son encargados todos hombres.

Respecto del papel de los encargados de la fábrica, una de las trabajadoras destaca la función de control que cumplen:

Te dicen que está filmando la cámara que enseguida le van a llamar al encargado, porque hay ahora todo cámara, para vigilar a la gente si está trabajando o no está trabajando... todo cámara. No puedes comer nada... prohibieron todo. (Rita, 37 años)

Los fragmentos exponen que, en efecto, se les atribuye a las mujeres características como responsabilidad, rapidez y constancia (mientras "los hombres se quejan", ellas trabajan "para terminar la tarea") que justificarían su mayor presencia en las viñas y en las cintas de las empacadoras. A su vez, los relatos evidencian una cierta apropiación de tales discursos y atribuciones de sentido por parte de las trabajadoras. En conjunto, el discurso de las entrevistadas traza pistas sobre la forma en que la división sexual del trabajo toma cuerpo en el empleo agrícola de la provincia de Mendoza. Por una parte, el relato de Rosa indica la distribución sexual de las jerarquías y puestos de trabajo, en función de la cual la mayoría de quienes trabajan en cintas de selección de frutas son mujeres, mientras que los encargados de supervisar la tarea son varones. Por otra parte, Rita expone el control al que son sometidas las trabajadoras, aspecto que nos permite coincidir con el estudio realizado por Elena Mingo ${ }^{(56)}$ que sugiere que la mayor responsabilidad y dedicación de las mujeres en el empleo puede ser resultado del autodisciplinamiento, vinculado al mayor control sobre la mano de obra femenina en general. En definitiva, los fragmentos expuestos indican que tanto fincas como fábricas constituyen espacios que no escapan a los procesos de segmentación sexual del mercado de trabajo. Procesos que se manifiestan en la creación de categorías laborales jerarquizadas por sexo, la mayor presencia femenina en los puestos de carácter subordinado y la naturalización de las cualificaciones laborales de las trabajadoras.

En el caso de las entrevistadas, la doble "valoración" otorgada por los empleadores por ser mujeres y migrantes, no redunda en mejores condiciones de empleo, sino que padecen todos los rasgos del trabajo precario: inestabilidad, falta de protección social y bajos niveles salariales ${ }^{(52)}$. Resulta conveniente preguntarse si tales condiciones solo afectan -o lo hacen distintivamente- a las mujeres migrantes, ya que gran parte de la bibliografía y de la información estadística disponible refiere a la precariedad generalizada de las condiciones de trabajo del agro. Sin embargo, como planteamos al inicio del documento, las desigualdades sexo-genéricas expresan inferiores condiciones de empleo para las trabajadoras agrícolas.

En lo que atañe a la inestabilidad, estudios previos documentan que los puestos exclusivamente masculinos corresponden a las tareas mejor pagadas y con posibilidades de acceso al empleo permanente, situación que ha sido informada para la agricultura de exportación de América Latina en general|(61), la fruticultura chilena ${ }^{(62)}$ la producción tabacalera de Jujuy ${ }^{(63)}$, la citrícola en Tucumán ${ }^{(63)}$ y la agroindustria de Mendoza ${ }^{(56)}$. Respecto de la protección social, el trabajo agrícola argentino se distingue por la falta de cobertura de seguridad social y los bajos niveles de registración, que resultan aun menores en las mujeres $^{(63)}$. El Registro Nacional de Trabajadores y Empleadores Agrícolas (RENATEA) fue un organismo público, dependiente del Ministerio de Trabajo de la Nación, que funcionó 
entre 2012 y 2015 . Sus funciones consistían en el registro de las y los trabajadores agrícolas, el control del cumplimiento por parte de los empleadores de las obligaciones que les imponía la ley y el desempeño de funciones de policía de trabajo rural. Al respecto, la delegación de Mendoza del RENATEA elaboró, en el año 2015, un informe que señala la baja tasa de registración de las mujeres en relación con los varones ${ }^{(64)}$. Finalmente, en cuanto a la remuneración, si bien no se cuenta con datos oficiales que analicen las desigualdades sexo-genéricas en el empleo agrícola argentino, estudios sobre la participación de mujeres como asalariadas en la agricultura intensiva de exportación latinoamericana señalan que -mayoritariamentelas mujeres no alcanzan a percibir siquiera los mínimos salariales legales ${ }^{(61)}$.

Ahora bien, ¿cuáles son las percepciones de las trabajadoras sobre sus condiciones de trabajo? Respecto de la inestabilidad, señalan que una práctica habitual de los empleadores, tanto en fincas como en fábricas de empaque, es contratarlas anualmente como trabajadoras temporarias aun cuando laboren todos los años para el mismo empleador. Esto redunda en menores derechos y protecciones sociales, especialmente las vinculadas con eventos reproductivos. La ley 26727 identifica tres formas de contratación en el empleo agrícola: trabajador/a temporario/a, permanente discontinuo y permanente, a cada una de estas categorías progresivamente le corresponden mayores derechos laborales. Aun cuando la segunda categoría sería la más ajustada a la actividad que desarrollan las entrevistadas, una práctica habitual de los empleadores del sector es registrarlas como trabajadoras temporarias para evitar cargas sociales y licencias correspondientes a las categorías permanentes.

Adicionalmente, detrás del argumento de la supuesta gran variabilidad de la producción, año a año las mujeres desconocen si serán convocadas a trabajar, durante qué período de tiempo y bajo qué condiciones, aspectos cuya causalidad el sector empresario la atribuye al volumen de producción. Así, las mujeres deben pagar las eventuales bajas productivas con su desempleo: "Todos los años tengo que pedir trabajo al cuadrillero o al encargado. Por ahí, si hay trabajo me da y si no, no" (Rita, 37 años).

Un aspecto destacado por las entrevistadas en cuanto a la registración del empleo es que se encuentra condicionada por la mediación de los cuadrilleros, que son los intermediarios que seleccionan a las y los trabajadores para laborar en las viñas, quienes generalmente también son migrantes con los que tienen relaciones vecinales y de cercanía. En el caso del empleo en la fábrica, para las mujeres, la figura del encargado es equivalente a la del cuadrillero en lo que hace a la contratación. La presencia de estos intermediarios no solo invisibiliza al efectivo empleador, a quien desconocen, aunque hayan trabajado en la misma explotación durante muchos años, sino que además limita las posibilidades de reclamo legal por las condiciones irregulares de contratación. En sus relatos señalan:

\begin{abstract}
Mire ahora, ahora ya no es con los patrones, ahora son cuadrilleros. Una sola persona se encarga de hablar con el patrón, no sé qué relaciones tendrán ellos... nosotros le pedimos trabajo al cuadrillero. El cuadrillero a nosotros no nos paga ni la jubilación, no nos paga nada [...] me da apuro decirle ¿me están aportando? No sé... me da vergüenza... que se yo, somos extranjeros y ... ¿Cómo le puedo decir? me da cosa preguntarle, encima que me da trabajo. (Alba, 52 años)
\end{abstract}

Por su parte, relata Rosa: "Que te fichen depende del cuadrillero, porque es el que te lleva y a veces no te da... no te ficha directamente" (la palabra "fichar" alude al acto de registrar formalmente la relación laboral). Las relaciones entre trabajadoras y cuadrilleros o encargados no escapan a las lógicas de dominación sexo-genérica que someten a las mujeres a diversas formas de violencia simbólica, física, sexual y económica. Rita señala:

En la fábrica donde yo estaba tampoco te dejaban hablar, pero el encargado de allá, creo que eran dos, si te conocía 
bien, charla con vos, juega con vos, pero si vos estás hablando y no te conoce viene y te reta. (Rita, 37 años)

Al respecto un estudio sobre las relaciones entre "enganchadores" y trabajadoras ha documentado desde situaciones de acoso en el ámbito laboral y discriminación en la forma de pago, hasta prácticas de control de la sexualidad como la exigencia de atestación de esterilidad para acceder al empleo o despidos por embarazo ${ }^{(65)}$.

En cuanto a la remuneración, es un aspecto que particulariza al segmento de las y los trabajadores agrícolas, ya que la paga por tarea redunda en jornadas extenuantes y cargas excesivas para lograr ingresos básicos ${ }^{(49)}$. Las trabajadoras manifiestan que el pago a destajo implica que lograr ciertos niveles salariales solo sea posible mediante una intensificación del esfuerzo físico, el empleo de la fuerza de trabajo de todo el grupo familiar o bien el aumento del tiempo de trabajo. Frecuentemente, se implementan todas estas opciones en forma conjunta:

Mire nosotros hemos trabajado con mis hijos... Ilenábamos el tacho, lo echábamos al camión y te daban una ficha. Y yo veía que mis hijos ya tenían una bolsita así de fichas... dios mire... me faltaban manos para cosechar [...] yo Ilenaba los tachos y ellos venían y acarreaban [...] iban y corrían ¿usted sabe cómo corrían? Descansaban un ratito y le dábamos otra vuelta. No descansaban ni diez ni quince... yo seguía cosechando y llenando los tachos hasta que ellos descansen. Yo les cargaba el tacho al hombro y ellos iban a vaciarlo al camión. (Alba, 52 años)

Ahora bien, la estrategia de trabajo en cuadriIla familiar, si bien permite alcanzar mayores ingresos, en ocasiones implica que las mujeres no perciban su remuneración, sino que esta queda en manos del varón de la familia:

Cuando Ilegué [a Mendoza] trabajé en el ajo con mi papá y mis hermanos, toda la familia junta. Pero nomás él cobraba, yo ni sé cuánto cobraba, él tenía todo y no me daba a mí. Yo no conocía la plata. Cuando empecé a trabajar aparte él me quitó la plata que yo tenía para comprar algo a mi hija. (Sandra, 29 años)

Otra trabajadora relata respecto al pago a destajo:

Te pagan lo que hacés, el trabajo, por ejemplo, las bolsas de zanahoria que hacés, por bolsa, al tanto. Si trabajabas ganas, si no trabajabas, nada, porque hay días, no todos los días se trabajaba. En la viña te pagan al tanto o al día, pero al día igual te dan tarea y por ahí tenés que rematarte para alcanzar lo que te piden [...] te dan demasiado, porque ya se abusan también. Al tanto se gana mucho más que por el día, pero también hay que rematarse porque muchas veces no te conviene, porque te dan muy pesada la tarea y no la sacás. Algunos si, y los hombres más, si sacan... porque ellos no sé, se rematan o no hacen bien. (Rosa, 40 años)

Algunos de los aspectos detallados hasta aquí nos permiten visualizar que el trabajo agrícola que realizan las migrantes en fábricas y fincas ocurre en el contexto de un mercado que las destina a los puestos más inestables, sin protección social y con ingresos insuficientes. Abordaremos a continuación las principales características del trabajo reproductivo y la forma en que este se articula con sus labores en el mundo de la producción.

\section{Condiciones de trabajo reproductivo: los hogares como lugar de trabajo y la separación entre casa y empleo como un límite difuso y conflictivo}

La reforma neoliberal del Estado y las crisis económicas de fines del siglo XX no solo impactaron en el empleo y la producción, sino que incidieron decisivamente en las 
estrategias familiares y comunales de sostenimiento cotidiano. El ingreso creciente de las mujeres al mercado de trabajo, el mantenimiento de la rígida división sexual del trabajo, los sistemáticos recortes en las políticas de protección social y salud, y la necesidad de las familias de emplear a la totalidad de sus miembros para afrontar situaciones de pobreza condujeron al aumento del trabajo remunerado y gratuito de las mujeres. La falta de acceso a la asistencia sanitaria y al cuidado infantil redundó en condiciones más penosas y mayores cargas en el trabajo doméstico femenino, que ha constituido una especie de colchón a la retracción estatal ${ }^{(38,66)}$.

En diversos países de América Latina se dispone de información estadística sobre el tema relevada en las encuestas de uso del tiempo. Los resultados corroboran la mayoritaria asignación de mujeres a tareas domésticas y de cuidado, señalan que la cantidad de tiempo de trabajo remunerado y no remunerado es inversamente proporcional en varones y mujeres, y destacan que el tiempo de trabajo destinado a cuidados aumenta para aquellas personas con menores ingresos, con menor nivel de instrucción, migrantes y residentes en zonas rurales ${ }^{(66)}$. Esto último es relevante porque las condiciones en que las mujeres ejercen el trabajo reproductivo no son uniformes sino que, según su clase, inscripción étnico-racial y nacionalidad, la cantidad de horas que le dedican, los instrumentos con que cuentan para su desarrollo y el acceso a servicios que contribuyen con estas tareas son altamente variables.

Los relatos de las trabajadoras agrícolas migrantes sobre la organización de la domesticidad confirman los datos mencionados: no solo aparecen como las responsables principales, sino que en ocasiones son las únicas encargadas de desarrollar tareas básicas para la sobrevivencia de sus familias, que desempeñan con escasa contribución de los servicios públicos, debido a las restricciones de acceso que les impone su condición de migrantes ${ }^{(2)}$. Estas responsabilidades que sostienen en los hogares no las eximen de importantes cargas de trabajo en el ámbito de la producción, sino que desde niñas, al tiempo que mantienen ritmos de trabajo en los campos iguales a los masculinos, al regresar a sus lugares de vida asumen tareas domésticas que, en contextos de escasez de recursos, se convierten en una carga excesiva ${ }^{(49)}$.

Entre las tareas reproductivas que asumen casi exclusivamente, el cuidado de hijas e hijos es identificado como una responsabilidad estrictamente materna. Así, el hecho de trabajar fuera del hogar y sus consecuencias para la crianza de niñas y niños deben ser afrontadas por las mujeres o sus allegadas. Frecuentemente, acuden a distintos acuerdos y arreglos de solidaridad con hijas mayores, hermanas y vecinas, o bien contratando cuidadoras pagas.

Cuando vivía como trabajadora golondrina tuve que dejar a mi hija con mi hermana, ella vivía en Tupungato. Por ahí los sábados la llevaba a la carpa, un día o dos días, o por feriado, de ahí la volvía a dejar y a veces yo iba a verla. $A$ veces pasaban dos semanas, siempre yo la venía a ver, pero ya eso me dolía. (Rosa, 40 años)

Frente a los requerimientos de cuidado de sus criaturas y la carencia de guarderías públicas en su comunidad, la concurrencia a los lugares de trabajo con niños/as pequeños/as resulta otra alternativa, aunque no siempre posible. Alba cuenta que desde temprana edad sus hijos e hijas la acompañaban a su trabajo en la finca: "Me cargaba la comida en la espalda, agua fresca, jugo para los chicos, té o yerbeado [...] llevaba todo eso en la espalda caliente y el bebé en los brazos, los más chicos caminando".

Otro elemento a considerar en el caso de las trabajadoras agrícolas es la particular forma en que se articulan trabajo productivo y reproductivo. A partir de sus experiencias, vemos que la separación de la casa y el trabajo, y la producción y la reproducción no resultan tan nítidas como suele presumirse. La casa se presenta como el lugar de una ardua jornada de trabajo, mientras que el espacio de empleo puede ser el lugar donde se vive, se cuida y se desarrolla la domesticidad. 
El pasaje de un ámbito a otro no implica la interrupción del trabajo, sino su continuidad, no solo porque múltiples propósitos ligados al mundo laboral se cumplen en los hogares, sino también debido a que diversas actividades asociadas al trabajo de reproducción, como el cuidado de hijos e hijas, acontecen en los lugares de empleo, particularmente en las fincas o chacras (término derivado del quechua chakra, y que designa un terreno de poca extensión dedicado a la agricultura).

Andábamos así en las cuadrillas de zanahoria, éramos golondrinas, sabíamos vivir directamente en las chacras, donde está la zanahoria, allá en las oriIlas armaban las carpas [...] La comida la hacíamos ahí nomás donde estábamos, en esa misma carpita donde dormíamos. (Rosa, 40 años)

Otra trabajadora puntualiza:

Desde los cinco o seis años ya los llevaba a la chacra... en aquellas épocas no había eso que decían "menores no pueden trabajar..." ni nada, todos podían ir conmigo, así que iban a trabajar todos conmigo y yo llevaba la comida en un táper [...] como para que ellos puedan comer bien y seguir trabajando, y trabajaban... todo el día afuera de la casa, con los chicos. (Alba, 52 años)

Ahora bien, estos difusos límites entre actividades productivas y reproductivas que caracterizan el trabajo en fincas y chacras, se tornan tensos para las trabajadoras al cumplir labores en fábricas, momento que las confronta con la rígida separación entre hogar y empleo. La fábrica constituye un lugar de severos controles, en la que resultaría inadmisible la presencia de sus hijos e hijas, por ejemplo. Además, el régimen de asistencia resulta más estricto que en las fincas, en las que si se ausentan una jornada no resultan expulsadas y pueden volver. Como señala Mariarosa Dalla Costa(67) en nuestra organización social, la familia y la fábrica funcionan como compartimentos tipo "gueto", por ello no es de extrañar que el paso de uno a otro sea doloroso. Rosa cuenta que durante el período de trabajo en la fábrica suspende cualquier tipo de consulta médica, propia o familiar, ya que no recibe autorización para faltar a trabajar:

Cuando termino la fábrica recién hago todos los estudios porque ahí tengo tiempo para ir, porque no te dan... cuando estás trabajando no podés ir. No tenés tiempo para ir. Sí o sí tengo que dejar de trabajar, recién ahí me llevo a mi nena y yo también me hago todos los estudios. Nunca he ido a la salita [centros de salud] cuando estaba en la fábrica, tuve esa suerte que nunca me enfermé.

Un aspecto por demás relevante son las modificaciones en la forma de inserción de las trabajadoras en el mundo del empleo en función de cambios en las cargas de trabajo reproductivo. El momento en que las mujeres transitan embarazos y tienen hijos e hijas de corta edad resulta un período en el que, a la par que aumenta la exigencia doméstica y de cuidados, se encuentran posicionadas en condiciones menos ventajosas para negociar con los empleadores. Ello implica que puedan percibir menores ingresos, no ser "seleccionadas" por los cuadrilleros e incluso que pueden ser despedidas. Por esta razón, en ocasiones las trabajadoras ocultan sus embarazos para que los cuadrilleros las sigan convocando a trabajar o para que no las despidan de la fábrica. También refieren que, si el momento de mayor demanda estacional de empleo coincide con el embarazo o el puerperio, pueden permanecer activas en los períodos en que correspondería una licencia. Rita relata que para no perder el puesto en la fábrica durante una temporada y para conservar el lugar que había logrado en la cinta de producción, comenzó a trabajar cuando su hija contaba con menos de 30 días de nacida, luego de una cesárea, de la cual aún no había recibido el alta médica. Rosa, en oposición, destaca que suspendía su trabajo durante los embarazos o cuando sus hijos eran 
pequeños: "De vez en cuando iba a trabajar cuando estaba embarazada [...] cuando los niños eran chicos me quedaba en la carpa, desde ahí iba al médico o a hacer los controles". Sandra, en torno a este tema, reflexiona: "Cuando estoy embarazada trabajo poco, un mes o dos [...] podés trabajar hasta los cuatro meses sin decirle a los cuadrilleros, porque no te llevan a trabajar, es un riesgo para ellos y para los patrones".

Los relatos expuestos en este apartado nos remontan a la categoría de sobreexplotación, planteada por Mies ${ }^{(44)}$ y Federici ${ }^{(38)}$ para caracterizar la situación de mujeres trabajadoras en la reproducción cotidiana de la vida. Se trata de fragmentos que evidencian las innumerables estrategias y los denodados esfuerzos mediante los cuales cada una afronta, soporta y/o resiste la precariedad de las condiciones de empleo y la escasez de recursos para sostener la vida de sus grupos de pertenencia. En suma, lo analizado en esta sección indica que el trabajo reproductivo y productivo se encuentran solapados cotidianamente, en múltiples momentos del año y en distintas etapas del ciclo vital de las mujeres entrevistadas. En otros momentos estas esferas se tensionan y conducen a que las trabajadoras tengan que optar entre su empleo y sus labores reproductivas. El solapamiento y la tensión entre espacios domésticos y laborales redundan en la intensificación y extensión de su jornada de trabajo o en la pérdida de posibilidades para lograr ingresos propios, aspectos que inciden de diversas maneras en su estado de salud.

\section{Las condiciones de trabajo y su incidencia en la salud: daños, malestares y padecimientos}

Hasta aquí hemos visto que la creciente participación de las mujeres como asalariadas agrícolas no supuso necesariamente un cambio beneficioso en sus condiciones de vida, ya que los cortos períodos de contratación y el pago por trabajo a destajo implican que obtener mejores ingresos solo sea posible a costa del desgaste físico de las trabajadoras ${ }^{(38,42)}$. A su vez, las condiciones en que ejercen el trabajo reproductivo también descansan sobre la superexplotación de su trabajo.

Abordaremos ahora la incidencia de estos procesos en la salud de las trabajadoras, refiriéndonos a tres aspectos: primero a las enfermedades y daños producidos por el trabajo, seguidamente a las dificultades en el acceso a los servicios de salud relacionadas con las condiciones de trabajo, finalmente referiremos a distintos malestares o padecimientos, que no configuran estrictamente en un cuadro clínico, pero que pueden ser entendidos en sentido amplio como parte de la salud laboral. Esta clasificación es realizada por algunos estudios para cubrir los diversos problemas de salud vinculados al trabajo y no solo las enfermedades consideradas como tales por la medicina ${ }^{(68)}$.

Respecto del primer punto, en consonancia con lo referido en otras investigaciones $^{(4,7)}$, las trabajadoras manifiestan -como daños o enfermedades recurrentes asociados al trabajo en fincas y fábricas- múltiples sintomatologías, especialmente dermatológicas y respiratorias, debido al uso de agrotóxicos y pesticidas, como también dolores posturales por la intensa demanda física del trabajo. Adicionalmente, manifiestan la recurrencia de accidentes laborales y el impacto nocivo de temperaturas extremas:

$$
\begin{aligned}
& \text { En la fábrica no te caloreas como en la } \\
& \text { finca, no te cansás por caminar mucho, } \\
& \text { en la fábrica solamente que estás } \\
& \text { parada eso te cansa, pero no es trabajo } \\
& \text { pesado... yo prefiero la fábrica, aunque } \\
& \text { hace calor, pero... no es tanto, o como el } \\
& \text { frío que pasas en la viña. (Rosa, } 40 \text { años) }
\end{aligned}
$$

Por su parte, Rita relata que, luego de siete años en la fábrica, logró conquistar el último puesto de la línea (en la evaluación final de la lata de conserva) que le permitía evitar el contacto con los productos de limpieza irritantes para la piel, la nariz y los ojos:

\footnotetext{
Hay muchos accidentes, se desmayan, se resbalan, se rompen la cabeza, se golpean la columna y se desvían la columna..
} 
[se caen] por el durazno que hay en el piso, hay agua, lavandina, es muy resbaloso. Siempre tenemos que lavar con detergente, con ese... soda cáustica... con detergentes muy fuertes... te queman, se te pela toda la mano, feo... por eso yo no quiero ir a la cinta [...] cuando entré a la cinta creo que se me hizo eso, de golpe apareció, pica, pica... es el ácido, un ácido fuerte que te dan para lavar... horrible te hace tu mano. La piel se hace bien finita, apenas que tocas ya se raja la mano [...] nos dicen que tenemos que usar guantes, pero los guantes no resisten, nos dan unos guantes descartables que no sirven, se rajan. (Rita, 37 años)

Otra de las trabajadoras puntualiza:

El trabajo en la fábrica, para mí, no es tan pesado. Pero sí tienen muchos químicos... cuando entrás los primeros días, yo siento que las manos en las noches te queman, te arden y después se te empieza a pelar [...] es peor cuando no usas guantes [...] pasa que nosotras compramos los guantes, a veces te los dan, a veces no, entonces nos prestamos los guantes con las mujeres de los otros turnos. (Rosa, 40 años)

Una médica clínica que se desempeña en el centro de salud de Ugarteche, en una entrevista que realizamos, manifiesta que suele atender a mujeres con múltiples daños producidos en el trabajo y destaca:

\footnotetext{
He visto quemaduras de primer, segundo o tercer grado en las manos por la falta de guantes o porque el químico que usan es tan tóxico que atraviesa la pared del guante. Y la gente en su necesidad no quiere decir que se trata de accidentes laborales.
}

La falta de horas de descanso es otro elemento constante referido por las trabajadoras como una de las condiciones de trabajo que afectan su salud ${ }^{(6,7)}$ lo que se halla estrechamente vinculado a la doble jornada. Cuando les pedimos a las trabajadoras que relaten un día habitual de trabajo manifiestan que, en general, su jornada inicia en la madrugada y se extiende hasta pasada la medianoche:

Yo dejaba a los niños míos que son cinco chicos y me iba a trabajar pasando el río [...] Yo trabajaba ahí hasta las doce y venía ligero les daba de comer y les mandaba a la escuela. Terminaba de comer limpiaba mi casa, así como ahora y me iba corriendo a trabajar de vuelta, si no había trabajo ahí me iba en las camionetas. Yo llegaba a las seis y ellos ya estaban acá. Cuando yo llegaba les hacía la comida en la tarde, en la noche lavaba, póngale que hasta la una de la mañana yo lavaba la ropa. Me acostaba y me levantaba a las cinco de la mañana y cocinaba. Mi diario era cocinar todos los días para ellos para que vayan a la escuela y mi esposo vaya a trabajar y yo vaya a trabajar. (Alba, 52 años)

Las trabajadoras identifican que la combinación de todas estas labores las lleva a dormir menor cantidad de horas de las que estiman como necesarias. Consecuentemente, manifiestan síntomas de fatiga recurrente y dolores corporales. Rosa destaca que los turnos rotativos que realiza en la fábrica alteran sus posibilidades de descanso, especialmente durante la jornada nocturna de trabajo:

Una semana de tarde, otra semana te toca a la mañana y otra semana a la noche. Son tres semanas rotativas. No me gusta el trabajo en la noche, nunca me gustó. Al otro día en la casa no se puede descansar. Porque uno está acostumbrada a dormir de noche. Pasa una semana así y casi sin dormir, porque no me queda otra que levantarme y hacer las cosas.

Respecto del acceso al sistema de salud, un aspecto relevante de los relatos es que este se ve limitado no sólo por la organización de los servicios sanitarios, sino también por las condiciones de trabajo, que se tensionan con 
el cuidado de su salud. La falta de registración les impide el goce de licencias por enfermedad o por cuidado de familiar enfermo, al tiempo que el pago por jornal implica que un día de reposo o dedicado a la asistencia de otra persona es un día sin remuneración, lo que conduce a que las mujeres evalúen la conveniencia de la pérdida de este ingreso frente a una situación de enfermedad. Es habitual que previo a la consulta médica desarroIlen estrategias de cuidado y que posterguen la búsqueda de asistencia médica hasta límites que ponen en riesgo su integridad física. La distancia entre los lugares de trabajo, los hogares y las instituciones sanitarias es aducida como una dificultad adicional:

No te entienden en la fábrica, por ahí decís ¿me pueden cambiar porque tengo turno mañana, tengo que llevar...? "No es mi problema, no sé qué harás, vos tenés que cuidar tu trabajo no yo, yo llamo a reemplazo y listo". Así te dicen pues "la gente me está rogando para trabajar". (Rita, 37 años)

Otra de las trabajadoras relata las dificultades para acceder a la atención médica ante una situación de aborto espontáneo:

[en la finca] Yo me enfermé, me agarré una hemorragia que estuve tres días en la carpa y no podía salir, no podía ni caminar y nadie... yo no le avisaba a nadie, yo tenía miedo y otra parte tenía vergüenza, no sé. Después que pasaron los días me fui a la salita, porque ya tenía el valor de caminar... En la salita me dijeron que había tenido una pérdida, me dieron unas pastillas y de ahí me tuve que ir derecho a trabajar a Santiago de Estero. (Rosa, 40 años)

Por otra parte, en cuanto a los malestares y padecimientos asociados al trabajo, los relatos de las trabajadoras muestran diversas situaciones. Una de ellas refiere al malestar causado por la estricta vigilancia y control del proceso de trabajo a los que son sometidas en el espacio de la fábrica. Esto conduce a que algunas de ellas valoren el trabajo en fincas como un espacio de mayor libertad, en el que habría un menor control patronal que en el rígido espacio fabril. Asimismo, la finca se presenta como un ámbito de socialización donde pueden intercambiar con otras mujeres:

[En la fábrica] te salís más cansada que ir a trabajar en la viña... en la viña caminamos, desbrotamos, pero estamos al aire libre [...] es tranquilo en la viña, a mí me gusta trabajar en la viña, charlás, conversás, hacés bromas, escuchás música, te reís, tranquilo en la viña. Pero acá parecés preso... no tenés que charlar, no tenés que jugar, no tenés con quien charlar porque yo estoy sola allá [...] te dicen que está filmando la cámara que enseguida le van a llamar al encargado, porque hay ahora todo cámara, para vigilar a la gente si está trabajando o no está trabajando... todo cámara. No puedes comer nada... prohibieron todo. (Rita, 37 años)

La violencia en los espacios de trabajo, suele ser otro de los padecimientos destacados por las trabajadoras, causante de elevados niveles de angustia. Esta violencia se despliega en dos sentidos, por su condición de migrantes y personas racializadas y por su condición de mujeres en un espacio tradicionalmente masculino:

Cuando trabajaba en el tabaco, el hijo del patrón me llevaba a descargar la estufa, al bajarme me empezaba a manosear... y alguien le contó al patrón, yo tenía miedo de contarlo... por ahí me van a dejar sin trabajo decía yo... no hablaba. Yo me callaba todo lo que me manoseaban, porque me daba miedo ir a trabajar con él, pero tenía que ir, porque yo necesitaba, si no ¿dónde iba a ir a trabajar? (Rita, 37 años)

La intensa carga y las precarias condiciones de trabajo, ha sido otro aspecto manifestado por las trabajadoras como motivo 
de sufrimiento subjetivo, que se suma al desgaste físico. La imposibilidad de satisfacer necesidades básicas pese a las intensas jornadas de trabajo, la tensión con las obligaciones domésticas, los arreglos del cuidado de hijas e hijos que implican separarse fueron señalados como una forma de padecimiento:

Mire me salieron ampollas, yo lloraba del dolor, porque no sabía escardar y no podía agarrar porque me habían salido ampollas en los dedos y lloraba... usted no sabe cómo lloraba... y había que hacerlo acá para poder sobrevivir... ¿si no lo hacía de qué iba a sobrevivir?... ¡Me salían unas ampollas que dios! y miraba mis manos y lloraba en el medio del terreno donde trabajaba ¡Qué dura la vida para tener algo en esta vida! Lloraba y seguía, no me importaba que la mano esté lastimada o sangrando, yo seguía. Y al otro día, quizás, trabajaba por acá con otros patrones. (Alba, 52 años)

Finalmente, las tareas de cuidado de familiares o dependientes con alguna enfermedad constituyen el origen de distintas formas de malestar. Además de que las condiciones en que acontece este cuidado atentan contra necesidades básicas de las trabajadoras, es visualizado por ellas como una forma concreta de limitación a su libertad. Este aspecto es significativo porque pocas veces se pone en consideración el malestar emocional que puede asociarse a las tareas de cuidado, que son investidas con el carácter de obligación moral, y se oculta el impacto de este trabajo en la salud de quien lo asume ${ }^{(2)}$ :

Cuando [mi madre] tuvo esa anemia estuvimos como diez días internadas las dos ahí [...] Les dije a mis hermanos si me podían reemplazar un día, porque necesitaba venir a bañarme, cambiarme de ropa... me dijeron que no, que no podían [...] usted sabe cómo lloraba yo... me sentía que estaba en la prisión, porque vio que usted entra cuando están internadas a cuidar y no sale a ningún lado... y yo no salía a ningún lado, me sentía allá adentro que me habían encerrado [...] así que me quedé hasta que le dieron el alta [...] yo dormía en el piso pelado, diga que era verano... no me había llevado ni una colcha. (Alba, 52 años)

Hasta aquí hemos procurado, a través de los relatos de las trabajadoras graficar las principales afecciones, dolencias o padecimientos vinculados con su trabajo. Resta analizar con mayor detenimiento las diversas estrategias de cuidado que despliegan, que no han sido objeto del presente artículo, pero que necesariamente requieren ser abordadas si se pretende tener un panorama acabado de la situación de salud-enfermedad de este grupo de mujeres.

\section{CONCLUSIONES}

En el recorrido del presente artículo hemos señalado las principales transformaciones ocurridas en las últimas décadas en la agricultura latinoamericana, que han delineado un campo cada vez más desigual. Las y los trabajadores agrícolas resultan un ejemplo crítico del entretejido de antiguas y novedosas formas de explotación del trabajo, como la convivencia del pago a destajo y la flexibilización laboral, todo lo que ha comportado consecuencias críticas para su salud. Destacamos también, que el mercado de trabajo en el que se insertan, se organiza con base en una segmentación social, sexual y racial de la mano de obra que destina a las mujeres migrantes a los puestos más precarios y peor remunerados.

Además, a partir de los relatos de las trabajadoras agrícolas migrantes, no solo pudimos dar cuenta del espacio del empleo como un ámbito marcado por la división sexual del trabajo, sino que además pusimos en relieve un hecho que los feminismos vienen señalando hace décadas: el trabajo de las mujeres no culmina al salir de la fábrica o al retornar de las fincas, sino que la jornada laboral se entrecruza de manera compleja con el trabajo gratuito que desempeñan en los hogares, sin el cual no sería posible la 
reproducción familiar y social. Este trabajo, que es desarrollado en condiciones de privación económica y con poco auxilio de los servicios públicos, se sostiene por la sobreexplotación de las mujeres.

Respecto de la incidencia en la saludenfermedad del solapamiento y las tensiones entre trabajo productivo y reproductivo, las experiencias denotan no solo los daños, enfermedades y accidentes vinculados al trabajo en fincas y fábricas; sino que también evidencian el agotamiento y malestar subjetivo que experimentan, que sobreviene cuando empleo y trabajo doméstico interfieren con el descanso, el cuidado de la propia salud o la libertad de movimiento. También visualizamos que la organización de los servicios de salud se combina con las precarias condiciones de trabajo y ambas se tornan un obstáculo para que las trabajadoras accedan a la atención médica cuando lo requieren.

A lo largo del artículo, a través de herramientas conceptuales feministas y los relatos de las trabajadoras, hemos buscado aportar a la comprensión de las complejas relaciones entre el trabajo y la salud de las mujeres. Uno de los supuestos que desarrollamos, es que las tareas domésticas y reproductivas constituyen una forma de trabajo, antes que "actividades" adicionales que las mujeres realizan. Por tanto, los procesos de trabajo que impactan en su salud no se reducen a los que acontecen en el ámbito del empleo remunerado. Consideramos que, de no incorporar esta dimensión, se corre el riesgo de desconocer uno de los principales aspectos generadores de enfermedad, malestar y sufrimiento para las trabajadoras.

\section{AGRADECIMIENTOS}

Agradecemos al Consejo Nacional de Investigaciones Científicas y Técnicas, que en el año 2014 otorgó la beca doctoral que sostiene la investigación cuyos resultados recoge el presente artículo. Además, brindamos un especial agradecimiento a cada una de las mujeres que aportó a esta investigación con sus relatos de vida y sus saberes.

\section{REFERENCIAS BIBLIOGRÁFICAS}

1. Falquet J. La règle du jeu. Repenser la co-formation des rapports sociaux de sexe, de classe et de "race" dans la mondialisation néolibérale. En: Dorlin E, Bidet-Mordrel A. Sexe, race, classe, pour une épistémologie de la domination. Paris: Presses Universitaires de France; 2009. p. 71-90.

2. Maure G, Linardelli MF, Anzorena C. ¿Autoatención o trabajo de cuidados?: el rol de mujeres migrantes bolivianas en el cuidado de familiares enfermos/as. VIII Jornadas de Investigación en Antropología Social Santiago Wallace. 2016; VIII:370-381.

3. Palacios-Nava M, Moreno-Tetlacuilo L. Diferencias en la salud de jornaleras y jornaleros agrícolas migrantes en Sinaloa, México. Salud Pública de México. 2004;46(4):286-293.
4. Camarena Ojinaga L, Von Glascoe C, Arellano García E, Zúñiga Violante E, Martínez Valdés C. Agroquímicos y mujeres indígenas jornaleras en Baja California. En: Cedillo L, Cano Robles F. Género, ambiente y contaminación por sustancias químicas. México: Instituto Nacional de Ecología; 2012. p. 67-78.

5. Lu JL. Relations of feminization of agriculture and women's occupational health: the case of women farmers in the Philippines. Journal of International Women's Studies. 2011;12(4):108-118.

6. Camarena Ojinaga L, Von Glascoe C, Martínez Valdés C, Arellano García E. Riesgos del trabajo y salud: percepción de mujeres indígenas jornaleras en el noroeste de México. Salud Colectiva. 2013;9(2):247-256.

7. Medel J, Riquelme V. La estacionalidad del empleo y la salud de las temporeras de la fruticultura en Chile. En: Lara Flores SM. Jornaleras, temporeras y bóias-frias: el rostro femenino del mercado de trabajo rural en América Latina. Caracas: Nueva Sociedad; 1995. p. 147-162.

8. Siqueira D, Benería L, Mostafa A. Mujeres trabajadoras rurales: salud, reproducción y ciudadanía en Brasil. En: Lara Flores SM. Jornaleras, temporeras y bóias-frias: el rostro femenino del mercado de trabajo rural en América Latina. Caracas: Nueva Sociedad; 1995. p. 163-180. 
9. Haro JA, Minjarez Sosa B. Determinantes de salud reproductiva en jornaleras de los campos agrícolas de Sonora: un enfoque epidemiológico sociocultural. En: VII Congreso Nacional de la Asociación Mexicana de Estudios del Trabajo; 2011; Yucatán.

10. Minjarez Sosa L. Exclusión en salud reproductiva: una realidad emergente en contextos rurales de migración indígena; caso: jornaleras agrícolas de la Estación Pesqueira, Sonora. En: Enríquez Acosta J, Guillén Lúgigo M, Valenzuela B, Jaime Rodríguez M. Sociedad, cultura y educación en Sonora: problemas, vulnerabilidad y cambio social. Sonora: Universidad de Sonora; 2015. p. 67-96.

11. Aranda P, Castro Vásquez M. El campo de la agroindustria en el noroeste de México y la salud de sus jornaleras: una propuesta de estudio. Salud Colectiva. 2016;12(1):55-70.

12. Mallimaci F, Giménez Béliveau V. Historia de vida y métodos biográficos. En: Vasilachis de Gialdino I. Estrategias de investigación cualitativa. Barcelona: Gedisa; 2006. p. 175-212.

13. De Souza Minayo MC. La artesanía de la investigación cualitativa. Buenos Aires: Lugar Editorial; 2013.

14. Moreno M, Torres L. Movimientos territoriales y dinámicas laborales: los migrantes bolivianos en la agricultura de Mendoza (Argentina). CriteriosCuadernos de Ciencias Jurídicas y Política Internacional. 2013;6(1):19-58.

15. Laurell AC. Proceso de trabajo y salud. Cuadernos Políticos. 1978;(17):59-79.

16. Laurell AC. La salud-enfermedad como proceso social. Cuadernos Médico Sociales. 1982;(19):1-11.

17. Laurell AC. Para la investigación de la salud de los trabajadores. Washington: Organización Panamericana de la Salud; 1993.

18. Menéndez E. El modelo médico y la salud de los trabajadores. Salud Colectiva. 2005;1(1):9-32.

19. Borderías C, Carrasco C, Alemany C. Las mujeres y el trabajo: rupturas conceptuales. Barcelona: Icaria; 1994.

20. Breilh J. La triple carga: trabajo, práctica doméstica y procreación; deterioro prematuro de la mujer en el neoliberalismo. Quito: Centro de Estudios y Asesoría en Salud; 1991.

21. Jassis M, Guendelman S. Maquiladoras y mujeres fronterizas ¿Beneficio o daño a la salud obrera? Salud Pública de México. 1993;35:620629.

22. Lara MA, Acevedo M. Incorporación de la mujer al trabajo remunerado: repercusiones para su salud reproductiva. En: Langer GA, Tolbert K. Mujer: sexualidad y salud reproductiva en México. México DF: Edamex; 1996. p. 119-151.

23. Brito J. Uma proposta de vigilância em saúde do trabalhador com a ótica de gênero. Cadernos de Saúde Pública. 1997;13(2):141-144.

24. Hilfinger Messias DK, Im E-O, Page A, Regev $\mathrm{H}$, Spiers J, Yoder L, Meleis AI. Defining and redefining work: implications for women's health. Gender \& Society. 1997;11(3):296-323.

25. Buvinić M, Giuffrida A, Glassman A. Gender inequality in health and work: the case of Latin America and the Caribbean. Washington DC: Inter-American Development Bank; 2002.

26. Cruz AC, Noriega M, Garduño M. Trabajo remunerado, trabajo doméstico y salud: las diferencias cualitativas y cuantitativas entre mujeres y varones. Cadernos de Saúde Pública. 2003;19(4):1129-1138.

27. European Agency for Safety and Health at Work. Gender issues in safety and health at work: a review. Luxemburgo: Official Publications of the European Communities; 2003.

28. Rubin-Kurtzman JR, Denman Champion CA, Monteverde GG. Cambios en el mundo del trabajo y la salud de las mujeres: una revisión desde América Latina [Internet]. Los Angeles: eScholarship, University of California; 2006 [citado 10 mar 2017]. Disponible en: https://tinyurl.com/y9xqqeuq.

29. Benería L. Reproducción, producción y división sexual del trabajo. Mientras Tanto. $1981 ;(6): 47-84$.

30. Davis A. Mujeres, raza y clase. Madrid: Akal; 2005.

31. Crenshaw KW. Cartografiando los márgenes: interseccionalidad, políticas identitarias y violencia contra las mujeres de color. En: Platero Méndez R. Intersecciones: cuerpos y sexualidades en la encrucijada; temas contemporáneos. Barcelona: Bellaterra; 2012. p. 87-122.

32. Kergoat D. Por una sociología de las relaciones sociales: del análisis crítico de las categorías dominantes a una nueva conceptualización. En: Borderías C, Carrasco C, Alemany C. Las mujeres y el trabajo: rupturas conceptuales. Barcelona: Icaria; 1994. p. 515-532. 
33. Anzorena C. Aportes conceptuales y prácticos de los feminismos para el estudio del Estado y las políticas públicas. Plaza Pública. 2014;7(11):17-41.

34. Young I. Marxismo y feminismo: más allá del matrimonio infeliz. El cielo por asalto. 1992;II(4):40-56.

35. Carrasco C. La economía feminista: una apuesta por otra economía. En: Vara MJ. Estudios sobre género y economía. Madrid: Akal; 2006.

36. Federici S. La reproducción de la fuerza de trabajo en la economía global y la revolución feminista inacabada. Contrapunto. 2014;(5):97-128.

37. Carrasco C. La economía del cuidado: planteamiento actual y desafíos pendientes. Revista de Economía Crítica. 2011;(11):205-225.

38. Federici S. Revolución en punto cero: trabajo doméstico, reproducción y luchas feministas. Madrid: Traficantes de Sueños; 2013.

39. Martínez Pizarro J. El mapa migratorio de América Latina y el Caribe, las mujeres y el género. Santiago: CEPAL; 2003.

40. Pizarro C. Partir y volver entre Argentina y Bolivia: trayectorias migratorias transnacionales e intersección de desigualdades [Internet]. Buenos Aires: VII Jornadas Santiago Wallace de Investigación en Antropología Social; 2013 [citado 10 mar 2017]. Disponible en: https://tinyurl.com/ycuy6ykl.

41. Magliano MJ, Domenech E. Género, política y migración en la agenda global: transformaciones recientes en la región sudamericana. Migración y desarrollo. 2009;(12):53-68.

42. Sassen S. Contrageografías de la globalización: género y ciudadanía en los circuitos transfronterizos. Madrid: Traficantes de Sueños; 2003.

43. Lara Flores SM. La feminización del trabajo asalariado en los cultivos de exportación no tradicionales en América Latina: efectos de una flexibilidad "salvaje". En: Lara Flores SM. Jornaleras, temporeras y bóias frías: el rostro femenino del mercado de trabajo rural en América Latina. Caracas: Nueva Sociedad; 1995. p. 13-34.

44. Mies M. Patriarchy and accumulation on a world scale: women in international division of labour. London: Zed Books; 1986.

45. Meillassoux C. Mujeres, graneros y capitales: Economía doméstica y capitalismo. México: Siglo XXI Editores; 1975.
46. Marini RM. Dialéctica de la dependencia: la economía exportadora. Sociedad y Desarrollo. 1972;(1):35-51.

47. Teubal M. Globalización y nueva ruralidad en América Latina. En: Giarraca N. ¿Una nueva ruralidad en América Latina? Buenos Aires: CLACSO; 2001.

48. Arizpe L, Aranda J. El empleo agroindustrial y la participación de la mujer en el desarrollo rural: un estudio de las obreras del cultivo de exportación de la fresa en Zamora, México. Michoacán: Organización Internacional del Trabajo; 1981.

49. Lara Flores SM. Violencia y contrapoder: una ventana al mundo de las mujeres indígenas migrantes, en México. Estudios Feministas. 2003;11(2):381-397.

50. Garcia A, Rofman A. Agrobusiness y fragmentación en el agro argentino: desde la marginación hacia una propuesta alternativa. Mundo Agrario. 2009;10(19):1-27.

51. Riella A, Mascheroni P. Asalariados rurales en América Latina. Montevideo: CLACSO; 2015.

52. Lara Flores $\mathrm{SM}_{i}$ Es posible hablar de trabajo decente en la agricultura moderno-empresarial en México? El Cotidiano. 2008;23(147):25-33.

53. Magliano MJ. Migración, género y desigualdad social: la migración de mujeres bolivianas hacia Argentina. Revista Estudios Feministas. 2009;17(2):349-367.

54. Goldberg A. Trayectorias migratorias, itinerarios de salud y experiencias de participación política de mujeres migrantes bolivianas que trabajaron y vivieron en talleres textiles clandestinos del Área Metropolitana de Buenos Aires, Argentina. Anuario Americanista Europeo. 2013;(11):199-216.

55. Benencia R. Inserción de bolivianos en el mercado de trabajo de la Argentina. En: Congreso de la Asociación de Estudios Latinoamericanos; 2009; Río de Janeiro.

56. Mingo E. Resistentes, comprometidas y conflictivas: obreras de la agroindustria frutícola en Argentina: una mirada desde la demanda de mano de obra. En: Riella A, Mascheroni P. Asalariados rurales en América Latina. Montevideo: CLACSO; 2015. p. 95-110.

57. Moreno MS. "De pasaditas no más voy": la participación de los migrantes bolivianos en las cosechas agrícolas de Mendoza; estudio de caso a partir de una etnografía multilocal. [Tesis de 
doctorado]. Mendoza: Universidad Nacional de Cuyo; 2017.

58. Pizarro C. La vulnerabilidad de los inmigrantes bolivianos como sujetos de derechos humanos: experimentando la exclusión y la discriminación en la región metropolitana de la ciudad de Córdoba [Internet]. Argentina: Ministerio de Justicia, Seguridad y Derechos Humanos; Instituto Nacional contra la Discriminación, la Xenofobia y el Racismo; 2008 [citado 10 mar 2017]. Disponible en: https://tinyurl.com/ydadzkl4.

59. Suárez B. Las manos más hábiles de los empaques: el aguacate y el mango en Michoacán. En: Lara Flores SM. Jornaleras, temporeras y bóiasfrias: el rostro femenino del mercado de trabajo rural en América Latina. Caracas: Nueva Sociedad; 1995. p.103-122.

60. Vazquez Laba V. Como hombres trabajando: participación laboral femenina con marcas de desigualdad de género en la agroindustria citrícola de la provincia de Tucumán, Argentina. REDD, Revista Espaço de Diálogo e Desconexão. 2009;1(2):1-12.

61. Valdés Subercasseaux X. Conclusiones. En: Soto Baquero F, Klein E. Empleo y condiciones de trabajo de mujeres temporeras agrícolas. Roma: Organización de las Naciones Unidas para la Agricultura y la Alimentación; 2012. p. 271-301.

62. Valdés Subercasseaux X. Cambios en la división sexual del trabajo y en las relaciones de género entre la hacienda y la empresa exportadora en Chile. En: Lara Flores SM. Jornaleras, tempo- reras y bóias-frias: el rostro femenino del mercado de trabajo rural en América Latina. Caracas: Nueva Sociedad; 1995. p. 61-72.

63. Aparicio S. Caso Argentina. En: Soto Baquero F, Klein E. Empleo y condiciones de trabajo de mujeres temporeras agrícolas. Roma: Organización de las Naciones Unidas para la Agricultura y la Alimentación; 2012. p. 11-141.

64. Registro Nacional de Trabajadores y Empleadores Agrarios, Delegación Mendoza. Aproximación a una caracterización del trabajo de las mujeres en el ámbito agrario de Mendoza. Mendoza: RENATRE; 2015.

65. Moraes Silva MA. Mujeres bóias-frias: el difícil arte de vivir en Brasil. En: Lara Flores SM. Jornaleras, temporeras y bóias-frias: el rostro femenino del mercado de trabajo rural en América Latina. Caracas: Nueva Sociedad; 1995. p. 73-85.

66. Marco Navarro F, Rico MN. Cuidado y políticas públicas: debates y estado de situación a nivel regional. En: Pautassi L, Zibecchi C, (coords.). Redefiniendo las fronteras del cuidado: agenda, derechos e infraestructura. Buenos Aires: Biblios; 2013. p. 27-58.

67. Dalla Costa $M$, James S. El poder de la mujer y la subversión de la comunidad. México: Siglo XXI; 1972.

68. Grimberg M. Demanda, negociación y salud: antropología social de las representaciones y prácticas de trabajadores gráficos 1984-1990. Buenos Aires: Facultad de Filosofía y Letras-UBA; 1997.

\section{FORMA DE CITAR}

Linardelli MF. Entre la finca, la fábrica y la casa: el trabajo productivo y reproductivo de trabajadoras agrícolas migrantes en Mendoza y su incidencia en la salud-enfermedad. Salud Colectiva. 2018;14(4):757-777. doi: 10.18294/ sc.2018.1395.

Recibido: 14 de marzo de 2017 | Versión final: 14 de enero de 2018 | Aprobado: 3 de mayo de 2018

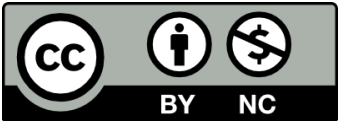
utilizada con finalidades comerciales, a menos que se obtenga el permiso. 